\title{
CYBERBRANDING SEBAGAI UPAYA MEMBANGUN BRAND AWARENESS SHOPEE INDONESIA
}

\author{
${ }^{1)}$ Chindy Ayu Anggraini, ${ }^{2)}$ Susie Perbawasari, ${ }^{3)}$ Heru Ryanto Budiana \\ 1) Prodi Hubungan Masyarakat Fakultas Ilmu Komunikasi Universitas Padjadjaran \\ 2) Prodi Hubungan Masyarakat Fakultas Ilmu Komunikasi Universitas Padjadjaran \\ ${ }^{3)}$ Prodi Hubungan Masyarakat Fakultas Ilmu Komunikasi Universitas Padjadjaran \\ Email ; ${ }^{1)}$ cindyanggraini5@ gmail.com, ${ }^{2)}$ susieperbawasari@yahoo.com, ${ }^{3}$ heru.ryanto@ unpad.ac.id
}

\begin{abstract}
In business competition as a newly established marketplace company within 2 years, Shopee needs to create a strategy to be able to compete with its competitors and can build awareness in the minds of its users, need good communication and also differentiate between Shopee with its users, in this case Shopee choose to do activities cyberbranding. This research aims to know the activities of Cyberbranding by Shopee Indonesia in building brand awareness through the delivery of information, creating interactivity, and making a difference. The research method used is descriptive method. To collect the data, researchers conducted indepth interviews, observations, and document studies. The results of this research are explain how Shopee's activities in providing information, Shopee convey information one of them through social media, various information is quite well delivered Shopee and adjusted to the needs of current Shopee users. In building interactivity, Shopee still uses social media as a direct communication medium between Shopee and its users, the various quiz contents of Shopee are able to build Shopee engagement with users, and in making a difference Shopee makes a free Postage program as a Shopee flagship program to attract users. Advice given by researchers in building brand awarenss is better if Shopee optimize the use of SEO (Search Engine Organization) in order to improve the position Shopee in search engines.
\end{abstract}

Keywords: cyberbranding, brand awareness, marketplace, Shopee.

\section{PENDAHULUAN}

Bisnis marketplace merupakan sebuah bisnis yang sedang berkembang pesat dalam beberapa tahun terakhir. Dari tahun ke tahun sudah semakin banyak marketplace yang hadir di Indonesia. Berawal dengan website yang sederhana kini marketplace di Indonesia terus berlomba mengembangkan berbagai fitur yang bisa ditawarkan. Tidak hanya di website, saat ini telah banyak marketplace yang mengeluarkan mobile aplikasi. Seluruh pengembangan fitur-fitur itu dibuat untuk memenuhi kebutuhan customer yang kerap ingin mudah dalam bertransaksi dan juga terus update mengikuti berbagai trend terbaru. Salah satunya adalah Shopee Indonesia sebagai marketplace yang juga bergerak di dunia online.

Shopee merupakan e-commerce berbasis marketplace yang menjadi wadah belanja online pertama yang berbasis mobile dikawasan Asia Tenggara dan Taiwan. Diluncurkan pertama kali pada bulan Desember tahun 2015 secara serentak di 7 Negara seperti: Indonesia, Singapura, Malaysia, Thailand, Vietnam, Filipina, dan Taiwan. Shopee merupakan sebuah platform 
yang secara khusus disesuaikan dengan kebutuhan pasar Asia Tenggara, yang menjadikan proses belanja online menjadi mudah, aman dan fleksibel, melalui sistem pembayaran dan dukungan sistem logistik yang kuat. Shopee menawarkan kepada penjual untuk mendaftarkan produk jualannya dan juga menawarkan kepada pembeli untuk dapat berbelanja berbagai penawaran menarik kapan saja, dan dimana saja, dengan keamanan transasksi yang terjamin. Shopee merupakan pusat perbelanjaan online dimana pengguna bisa mendapatkan update terkini dari penjual yang diikuti.

Berbeda dengan marketplace lain yang lebih dahulu meluncurkan website, Shopee lebih dulu mengeluarkan dan lebih fokus dengan mobile aplikasi, melihat trend saat ini dengan berbagai kegiatan yang mudah dilakukan menggunakan smartphone dan juga internet. Hal tersebut dijelaskan oleh Dinda Sarasanisa fatimah sebagai Senior Public Relations Associate Shopee Indonesia.

"Dari 2015 kita memposisikan diri sebagai marketplace yang mobile base jadi awalnya kami mengeluarkan aplikasi di handphone bukan di desktop, kalau misalnya mungkin temen-temen yang lain memulainya di desktop lalu karena melihat trend sekarang banyak menggunakan handphone baru dibuat aplikasi di handphone-nya, kalo Shopee memang dari 2015 kita langsung bikin untuk mobile phone baru setelah dalam perkembangannya kita mengakomodir yang di desktop.” (Fatimah, 2017).
Belum genap dua tahun berdiri, Shopee telah berkembang cukup pesat. Saat ini applikasi Shopee telah di unduh sebanyak lebih dari 8 juta. Setiap harinya Shopee telah melayani lebih dari 200.000 transaksi. Pada tahun 2017 ini Shopee juga sempat menjadi top number one shopping app di Google play.

Walaupun Shopee pernah mencapai top number one shopping app, namun perjalanan Shopee tidak selalu berjalan mulus, sebagai marketplace Shopee memiliki beberapa kompetitor lain yang telah berdiri lebih dulu seperti Bukalapak dan Tokopedia. Tentunya mereka telah menjadi top off mind dimata audience. Oleh karena itu, perlu adanya strategi yang dilakukan Shopee agar mampu mencapai kembali dan mempertahankan pencapaiannya sebagai top number one shopping app. Hal ini tentu menjadi salah satu tantangan untuk Shopee melakukan beberapa rangkaian strategi agar dapat kembali memperebutkan posisi teratas.

Shopee memilih memanfaatkan penggunaan media online seperti media sosial dan online advertising untuk melaksanakan seluruh kegiatan branding. Pemilihan menggunakan media online sebagai salah satu media untuk memperkenalkan dan penyebaran informasi Shopee dilakukan menurut Dinda Sarasa Fatimah karena dirasa lebih efektif, dengan biaya yang tidak terlalu besar namun mampu mencangkup pasar yang lebih luas, seluruh kegiatan yang dilakukan tersebut 
dalam upaya membangun brand awareness Shopee agar pengguna marketplace dapat mengingat Shopee di setiap pemenuhan kebutuhan mereka. (Fatimah, 2017).

Kegiatan online yang dilakukan Shopee selanjutnya disebut cyberbranding. Cyberbranding, menurut Alan Bergstrom pada prinsipnya adalah kegiatan melakukan brand secara online melalui media internet, yang tidak berbeda dengan melakukan kegiatan brand pada umumnya, seperti; memilih nama, merancang desain logo serta mengenalkannya melalui iklan dan kampanye. (Bergstrom, 2000). Kegiatan cyberbranding setidaknya memiliki tiga tujuan yang perlu dicapai oleh suatu perusahaan, yang pertama adalah memberikan informasi secara online mengenai perusahaan tersebut dan sesuai dengan apa yang diharapkan oleh pengguna Shopee. Kedua perusahaan perlu membangun interaktivitas antar Shopee dan juga audience secara online. Selanjutnya adalah adanya perbedaan yang dilakukan oleh perusahaan baik dari segi strategi maupun keunggulan yang dimiliki. Ketiga hal tersebut yang akhirnya akan membangun brand awareness dari sebuah perusahaan.

Melakukan cyberbranding pada dasarnya merupakan langkah strategis untuk menjangkau publik yang lebih luas dan tanpa batas. Mekanisme pertukaran informasi antara pengguna dengan Shopee melalui media internet menjadi langkah awal untuk mendekati pasar. Selanjutnya Shopee perlu membuat dan memperkuat strategi-strategi untuk dapat mengembalikan dan mempertahankan posisinya, sehingga seluruh tujuan yang diharapkan dari kegiatan online tersebut dapat tercapai. Hal itu yang kemudian menarik perhatian peneliti untuk dapat mengetahui lebih dalam mengenai bagaimana kegiatan cyberbranding dalam membangun brand awareness Shopee Indonesia.

Teori pendukung yang digunakan peneliti dalam melakukan penelitian yang pertama adalah mengenai Online Public Relations. Internet membuat para pelaku PR juga memanfaatkan media online karena media ini memang sudah tidak dapat dihindarkan lagi. Para pebisnis memilih beralih menggunakan E-PR karena dapat memanfaatkan media elektronik seperti internet untuk membangun hubungan antara bisnis di suatu perusahaan dan public audiens. Ribuan one-to-one dapat dibangun secara simultan melalui media internet karena sifatnya yang interaktif. (Onggo, 2004:2).

E-PR adalah inisiatif PR atau Public Relations yang menggunakan media internet sebagai sarana publisitasnya. Di Indonesia inisiatif PR ini lebih dikenal dengan istilah Cyber Public Relatios. Jika diuraikan E-PR dapat diartikan sebagai berikut: $\mathrm{E}$ adalah Electronic, "e" didalam E-PR sama halnya dengan "e" sebelum kata mail atau commerce yang mengacu pada media cetak elektronik 
internet. Mengingat popularitas dan multifungsi media internet, media ini dimanfaatkan pula oleh para pelaku PR untuk membangun merek (brand) dan memelihara kepercayaan (trust). P adalah Public, "public" disini mengacu bukan hanya pada public namun pada konsumen. Public juga tidak mengacu hanya pada satu jenis pasar konsumen, namun pada berbagai pasar atau publik audiens. Media internet bisa memudahkan kita untuk menjangkau mereka dengan lebih cepat atau sebaliknya, memudahkan mereka untuk menjangkau kita. $\mathrm{R}$ adalah "Relations", Relations merupakan hubungan yang harus dipupuk antara pasar dan bisnis anda. Itulah kunci kepercayaan pasar agar suatu bisnis berhasil. Menariknya, melalui media internet hubungan yang sifatnya one-to-one dapat dibangun dalam waktu yang cepat karena sifat internet yang interaktif. Hal ini berbeda dengan public konvensional. Dalam public konvensional anda harus menjangkau mereka dengan sifat one-to-many. Itulah sebabnya internet merupakan media pembangun hubungan yang paling ampuh dan cepat serta luas saat ini (Onggo, 2004:1-2).

$$
\text { Cyberbranding adalah sebuah }
$$

kesempatan untuk menciptakan awareness dari suatu brand secara online, membangun pengakuan terhadap nama dan logo, mengkomunikasikan pesan dari suatu brand, mendorong traffic website, membangun identitas terhadap publik primer dan sekunder, membangun pelanggan berbasis online, meningkatkan penjualan melalui internet, dan menciptakan reputasi sehingga semakin banyak suatu brand disebut dapat memunculkan perasaan akan sebuah pengalaman yang menyenangkan.

Penelitian ini menggunakan konsep cyberbranding, dimana dalam memahami cyberbrand ada hubungannya dengan tiga teori "I", yang dikutip oleh Deidre Breakenridge dari Advertising Age dalam buku Cyberbranding Brand Building in the Digital Economy:

"understanding the cyberbrand has to do with the three " $i$ " theory. The first " $i$ " is information, which does not necessarily mean simply company brochure information, but information that an audience expects from a brand in cyberspace (which depends on the brand's characteristics and attributes). The second " $i$ " is interactivity, that hands-on experience that adds a new dimension to any brand pre-Internet. The third " $i$ " is instinct, to avoid emulating another company's Web site branding and market- ing efforts simply because it looks like a good idea." (Breakenridge, 2001:47)

Berdasarkan penjelasan tersebut, dapat diketahui bahwa cyberbrand harus meliputi teori tiga "i" diantaranya: informasi, interaktivitas, dan insnting. Informasi yang disampaikan bukan hanya berupa company profile ataupun berbentuk brosur, tetapi lebih kepada menyampaikan informasi yang sesuai dengan apa yang audiens harapkan dari sebuah brand dalam ruang lingkup online yang bergantung pada karakteristik dan atribut suatu 
brand. Interaktivitas, merupakan sebuah pengalaman yang menjadi dimensi baru bagi brand yang telah terbentuk sebelum mengenal online. Maksud interaktif disini adalah keunikan interaksi yang bisa dibangun melalui online seperti komunikasi one to one yang menjadi lebih mudah, penyebaran informasi lebih cepat, feedback yang lebih mudah didapat. Insting, adalah tidak berusaha meniru upaya branding perusahaan lain baik dari isi website ataupun upaya marketing, sehingga menghasilkan perbedaan dibandingkan perusahaan lainnya.

Kesadaran merek (brand awareness) adalah kesanggupan seorang calon pembeli untuk mengenali atau mengingat kembali bahwa suatu merek merupakan bagian dari kategori produk tertentu. Aaker dalam (Rangkuti, 2009:39).

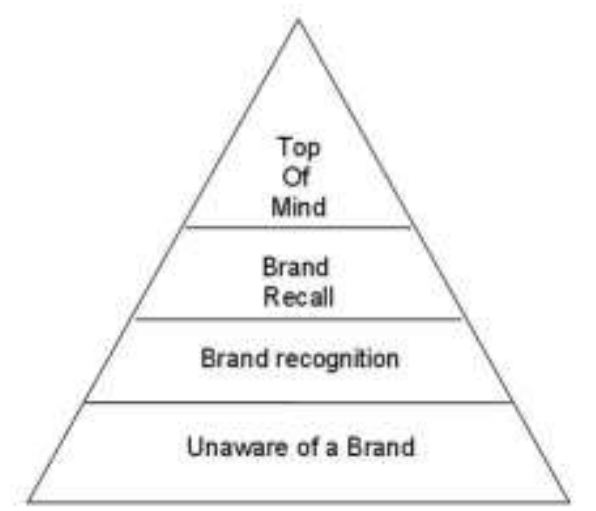

Gambar 1. Piramida Brand Awareness

Penjelasan mengenai piramida Brand awareness dari tingkat terendah sampai tingkat tertinggi adalah: (1.) Unware of Brand (tidak menyadari merek) merupakan tingkat yang paling rendah dalam piramida kesadaran merek, di mana konsumen tidak menyadari akan adanya suatu merek. (2.) Brand Recognition (pengenalan merek), tingkat minimal dari kesadaran merek. Hal ini penting pada saat seorang pembeli memilih suatu merek pada saat melakukan pembelian. (3.) Brand Recall (pengingatan kembali terhadap merek) yaitu pengingatan kembali terhadap merek didasarkan pada permintaan seseorang untuk menyebutkan merek tertentu dalam suatu kelas produk. Hal ini diistilahkan dengan pengingatan kembali tanpa bantuan, karena berbeda dari tugas pengenalan, responden tidak perlu dibantu untuk memunculkan merek tersebut. (4.) Top of mind (puncak pikiran) Apabila seserorang ditanya secara langsung tanpa diberi bantuan pengingatan dan ia dapat menyebutkan satu nama merek, maka merek yang paling banyak disebutkan pertama sekali merupakan puncak pikiran. Dengan kata lain, merek tersebut merupakan merek utama dari berbagai merek yang ada di dalam benak konsumen. (Rangkuti, 2009:40-41).

Berdasarkan penjelasan sebelumnya, maka dirumuskan beberapa rumusan masalah dari penelitian ini diantaranya: (1.) Baimana Shopee Indonesia dalam memberikan informasi untuk membangun brand awareness? (2.) Bagaimana Shopee Indonesia dalam membentuk interaktivitas untuk membangun brand awareness? Bagaimana Shopee Indonesia dalam membuat 
perbedaan untuk membangun brand awareness?

\section{METODE PENELITIAN}

Penelitian ini menggunakan pendekatan kualitatif dengan jenis deskriptif. Jenis penelitian deskritif dapat mengungkap dan mendeskripsikan atau menjelaskan sebuah peristiwa sehingga dapat diketahui keadaan sebenarnya. Alasan peneliti menggunakan metode deskriptif-kualitatif adalah karena peneliti ingin memaparkan dan mendeskripsikan tentang apa yang terjadi di lapangan atau yang ada dalam penelitian ini mengenai kegiatan cyberbranding Shopee Indonesia dalam membangun brand awareness.

Penelitian ini menggunakan teknik sampel bertujuan (purposive sample). Teknik sampel bertujuan atau purposive sample adalah teknik pengambilan sumber data dengan pertimbangan tertentu. Pertimbangan tertentu dalam hal ini adalah ukuran peneliti menentukan siapa yang akan diwawancara atau informsi seperti apa yang dibutuhkan dalam penelitian. Peneliti telah menetapkan kriteria yang tepat dan sesuai bagi penelitian ini, yaitu: Pertama, merupakan karyawan di PT Shopee Internasional Indonesia. Kedua, berada dibawah divisi marketing Shopee Indonesia. Ketiga, terlibat langusng dengan kegiatan branding Shopee Indonesia terutama secara online dan Keempat, bersedia meluangkan waktu ditengah jam kerja untuk diwawancarai oleh peneliti.

Berdasarkan kriteria tersebut, maka narasumber atau informan dalam penelitian ini, adalah: Dinda Sarassafatimah, Senior Public Relations Associate Shopee Indonesia. Almira Ayu Ningtyas, Market analyst Shopee Indonesia. Putri Nindya Wulandari, Social Media Content Writter Shopee Indonesia. Icha Bella, Public Relations Associate Shopee Indonesia dan Vitantri Anggayasti, Online Marketing Shopee Indonesia.

\section{HASIL DAN PEMBAHASAN}

Besarnya perkembangan jumlah pengguna internet di Indonesia dan melihat karakter pengguna internet Indonesia dalam menggunakan media sosial, menjadi peluang bagi Shopee yang merupakan sebuah marketplace untuk juga melakukan strategi pemasaran melalui media online. Shopee menyadari bahwa melakukan kegiatan online memberikan keuntungan yang cukup besar, namun tetap hal ini dilakukan bersamaan dengan kegiatan offline. Beberapa kegiatan online yang dilakukan Shopee yakni membuat google ads, bekerjasama dengan influencer dan memaksimalkan pemanfaatan media social. Shopee memanfaatkan dengan baik penggunaan media sosial baik untuk melakukan pemasaran, memberikan informasi, dan juga melakukan interaksi dengan pengguna. 
Public Relations Shopee mengatakan, sesuai dengan karakteristik pengguna Shopee saat ini, Shopee ingin menjadi destinasi belanja nomor satu di Indonesia, yang juga dapat memberikan pengalaman belanja online yang menyenangkan, dan aman. Dengan mengikuti trend masa kini, Shopee berusaha memberikan kemudahan berbelanja dengan fitur-fitur yang mempermudah pengguna baik untuk seller ataupun buyer yang bertransaksi di Shopee. Hal tersebut Shopee sekaligus ingin membuat para seller senang dalam mengembangkan bisnisnya dan juga memperluas pasar mereka.

Berdasarkan hasil penelitian yang dilakukan oleh peneliti terdapat beberapa Informasi yang diberikan Shopee kepada penggunanya. Kegiatan pertama Shopee dalam melakukan informasi dilakukan pada platform Shopee itu sendiri menggunakan aplikasi dan website Shopee. Shopee berusaha menghadirkan fitur-fitur yang mempermudah penggunanya untuk berbelanja maupun berjualan di Shopee. Shopee juga berusaha menghadirkan fitur yang memberikan keamanan dalam melakukan transaksi Shopee, dengan memberikan fitur yang mempermudah dalam berbelanja. Shopee ingin menyampaikan bahwa Shopee merupakan marketplace yang aman dan mudah digunakan. Hal tesebut disampaikan oleh Icha Bela dalam pernyataan berikut:

"yang pasti Shopee ingin menjadi destinasi belanja online nomer satu di Indonesia, since kita menjadi mobile commerce kita ingin menyajikan fitur belanja yang mudah yang simple karena kan kita ingin gantiin sistemnya orang belanja di social media, sekarang kan banyak orang jualan di instagram sedangkan kalau kamu sadari kalau belanja di instagram mereka belum punya metode pembayaran yang aman banyak banget penipuan dan segala macam, logistiknya juga kita tanggung sendiri, sedangkan Shopee dengan fiturfitur kita yang kaya social media, yang mudah dan aman, gak perlu buka laptop sebenernya itu sama aja kaya social media, tapi kita punya metode pembayaran yang aman.” (Bella, 2017).

Cara lain Shopee dalam menyampaikan informasi menurut Putri Nindya Wulantri, yakni dengan mengoptimalkan penggunaan media social. Beberapa konten media sosial yang dibuat Shopee diantaranya adalah penyampaian informasi promo, edukasi cara berjualan di Shopee untuk seller, kuis yang berkaitan dengan campaign Shopee yang sedang berlangsung, dan juga informasi event. (Wulantri, 2017). Shopee menggunakan media sosial dengan memberikan konten yang mengedukasi penggunanya. Contohnya terkait cara menggunakan Shopee hingga berbagai tips berjualan dan berbelanja. Selain itu juga, konten yang disajikan berusaha menyampaikan citra yang ingin dibangun Shopee yakni tempat belanja online yang Fun, Young, and dinamis dengan menghadirkan konten-konten yang menyenangkan seperti kuis dan promo.

Ketiga, Shopee menyampaikan informasi melalui digital ads yang dibuatnya, 
dalam penggunaan digital ads. Shopee berusaha menarik pengguna baru dan juga sekaligus untuk menyampaikan segmentasi dan positioning Shopee secara tersirat. Ketiga hal tersebut diharapkan Shopee dalam mengedukasi penggunanya sekaligus membangun awareness Shopee. Saat ini digital ads masih terus digunakan untuk membangun awareness Shopee karena masih dianggap menjadi salah satu aktivitas online Shopee yang cukup efektif, seperti apa yang disampaikan oleh Vitantri Anggayasti tim marketing online Shopee Indonesia:

"Digital ads jelas mempengaruhi banget untuk peningkatan pengguna Shopee, karena kita masih tahap develop, dan kita masih baru banget kan, jelas kita harus pakai iklan, tapi yang paling penting dari penggunaan dunia online tuh kaya gak perlu tanya lagi ke orang-orang, semuanya bisa kita direct dan respon mereka bisa kita lihat dan kita ukur. Untuk jumlah peningkatanya sendiri I think its more than $50 \%$ sebagai pengguna aktif yaaa, bahkan untuk semua faktor ya visitor, user, ataupun seller." (Anggayasti, 2017).

Berdasarkan hasil temuan yang didapatkan oleh peneliti, terdapat beberapa interaksi yang dibangun oleh Shopee. Bentuk Interaksi pertama yang berusaha dibangun Shopee yakni melalui media social. Selain melalui kegiatan offline Shopee berusaha membangun interaksi melalui online sehingga dapat dilakukan tanpa bertatap muka langsung. Media sosial dimanfaatkan Shopee sebagai customer service $24 \mathrm{jam} / 7$ dan juga menjadi media untuk pengguna Shopee agar dapat memberikan masukan kepada Shopee. Shopee juga berusaha membangun engagement melalui konten promo dan kuis.

Kegiatan Shopee menggunakan berbagai cara dalam membangun interaksi dengan penggunanya melalui media social, yaitu membuat konten menarik di setiap media sosial yang digunakan. Contohnya pada media sosial instagram, Shopee sering membuat kuis berhadiah yang sekaligus untuk meminta pendapat dari penggunanya. Pada media sosial twitter Shopee cenderung lebih mengarahkan untuk memberikan informasi dan tempat yang digunakan oleh pengguna untuk mengajukan complain. Pada facebook bentuk interaksi yang dilakukan yakni untuk complain dan juga sharing pada live facebook. Selain itu pada youtube Shopee membuat kuis dalam bentuk video

Shopee juga berusaha membangun interaksi dengan pengguna melalui pemanfaatan iklan Shopee. Tidak hanya ditayangkan pada youtube dan televisi, Shopee mengolah iklan agar dapat menjadi salah satu tools untuk dapat berinteraksi dengan membuat kuis parodi iklan Shopee. Shopee ingin memanfaatkan iklan sebagai salah satu media untuk berinteraksi dengan membuat kuis parody iklan Shopee Hal ini menjadi keuntungan tersendiri bagi Shopee. Iklan ini membantu membangun engagement yang diinginkan. Iklan Shopee juga membantu mnyebarluaskna informasi terkait shopee 
dengan semakin luas dan mendapatkan banyak viewer.

Berdasarkan data yang didapatkan oleh peneliti, yang pertama shoppe lebih mengarahkan penggunanya menggunakan aplikasi. Dengan menentukan positioning Shopee sebagai marketplace berbasis mobilebase, dimana platform penggunaan Shopee lebih di fokuskan pada penggunaan aplikasi. Meskipun, dalam perkembangannya Shopee masih menggunakan website, namun Shopee lebih banyak mengarahkan penggunanya untuk menggunakan aplikasi. Shopee menawarkan kemudahan kepada para penggunanya agar dapat berbelanja dimanapun dan kapanpun dengan mudah dengan fitur-fitur seperti media sosial yang juga mudah untuk digunakan. Menopang perkembangannya, Shopee juga menyajikan platform website agar penggunanya dapat tetap melakukan transaksi Shopee tanpa handphone. Hingga kini fokus Shopee masih tetap pada mobile aplikasi Shopee.

Perbedaan terakhir yang berusaha dibangun Shopee adalah membangun Brand awareness dengan membuat program Gratis Ongkos Kirim. Gratis ongkir yang diberikan Shopee tidak hanya dilakukan dalam waktu tertentu, melainkan Gratis Ongkir Shopee dibuat tanpa jangka waktu tertentu. Program ini juga dibuat menyesuaikan dengan kebutuhan pengguna Shopee saat ini, Shopee membuat program Gratis Ongkir tanpa batasan jarak dan waktu ini dianggap cukup efektif untuk menarik pengguna, melihat banyaknya pengguna yang antusias menggunakan Shopee karena program ini. Alasan mengenai dibuatnya program Gratis Ongkir dijelaskan oleh Dinda Sarasannisa Fatimah pada pernyatanya berikut:

"Kita punya program gratis ongkir, jadi ini
memang salah satu strategi kita karena kita
tau biaya ongkos kirim sering kali menjadi
penghambat buat orang-orang belanja
online, jadi kita putuskan untuk membuat
program gratis ongkir dan masih berlanjut
sampai sekarang, dan ini berlaku di seluruh
Indonesia, tapi memang ada syarat
tertentu, setiap kali kita akan selalu review
syarat-syarat tertentu dan kayaknya tidak
terlalu memberatkan, karena kalau kita
compare dengan marketplace lain kan
mereka menjadi gratis ongkir hanya
practical misalnya pada saat ramadhan
atau pada saat mereka ulangtahun, tapi
kalau Shopee itu selalu ada di sepanjang
tahun." (Fatimah, 2017).

Sebagai perusahaan yang bergerak di dunia online, Shopee menggunakan strategi cyberbranding sebagai cara untuk mendapatkan awareness dari audience. Melihat Shopee sebagai perusahaan marketplace tentunya seluruh kegiatan transaksi yang dilakukan pelanggan akan melalui online. Hal tersebut yang menjadi acuan bagi Shopee untuk membangun awarenessnya dalam kegiatan online yang dilakukannya.

Shopee menyadari bahwa perusahaan marketplace telah cukup menjamur di Indonesia, untuk itu Shopee ingin menjadi 
marketplace yang dapat memberikan pengalaman belanja yang menyenangkan bagi penggunanya. Shopee juga berusaha menjadi marketplace yang dipercaya, aman, dan mudah digunakan, Shopee ingin menjadi marketplace yang membuat penjual merasa senang dalam memajukan bisnisnya dan pembeli merasa senang dengan produk-produk yang ditawarkan Shopee. Hal tersebut berusaha disampaikan Shopee kepada penggunanya melalui berbagai kegiatan online yang dilakukan.

Hal pertama yang dilakukan Shopee dalam penyampaian informasi adalah langsung menyampaikan informasi pada aplikasi Shopee yang nantinya akan bersentuhan langsung dengan penggunanya. Shopee sendiri memposisikan dirinya sebagai marketplace berbasis mobile app pertama di Indonesia. Hal ini cukup sesuai dengan apa yang disampaikan oleh Freddy Rangkuti dalam bukunya, bahwa dalam membangun merek yang kuat tentu memerlukan fondasi yang kuat, salah satunya yakni, memiliki positioning yang tepat. Merek dapat di-positioning-kan dengan berbagai cara, misalnya dengan menempatkan posisinya secara spesifik di benak pelanggan. Membangun positioning adalah menempatkan semua aspek dari brand value secara konsisten sehingga selalu menjadi nomor satu dibenak pelanggan. Dalam hal ini Shopee berusaha memposisikan dirinya sebagai marketplace berbasis mobile app yang mudah digunakan dimana saja dan kapan saja.

Shopee berusaha menjadi perusahaan yang mampu beradaptasi dengan perkembangan teknologi. Hal tersebut sesuai dengan salah satu tools cyberbranding yang disampaikan Daniel Rowles dalam bukunya bahwa untuk melakukan kegiatan digital branding yang lebih efektif perlu adanya penggabungan perubahan dan potensi tambahan yang komplek. Hal tersebut sebagai bagian dari masa depan, itu berarti teknologi dibelakang website perlu beradaptasi dengan cepat keperangkat yang akan banyak digunakan user. (Rowles, 2014:114).

Cara lain yang digunakan Shopee untuk menyampaikan informasi yakni dengan memaksimalkan penggunaan media social. Icha Bella menjelaskan alasan Shopee memilih menggunakan media sosial karena disesuaikan dengan habit masyarakat Indonesia, dimana sering kali menggunakan media social. Selain itu juga karena media sosial memiliki penetrasi yang tinggi sehingga media sosial menjadi media yang mudah dan cukup efektif digunakan untuk saat ini. Keputusan Shopee memilih menggunakan media sosial sebagai salah satu media untuk menyampaikan informasi sesuai dengan salah satu tools cyberbranding yang disebutkan Rowles dalam bukunya.

Media pemberian informasi Shopee selanjutnya juga menggunakan digital ads, 
Vitantri Anggayasti tim marketing online Shopee Indonesia menjelaskan bahwa saat ini digital ads masih menjadi cara yang efektif untuk menarik pengguna bagi Shopee dan juga untuk membangun awareness. Sebagai perusahaan yang baru saja berdiri kurang lebih dua tahun Shopee menggunakan digital ads untuk menarik pengguna baru. Selain itu dengan digital ads Shopee dapat lebih mudah mengarahkan ads kepada audiens yang ingin dituju. Menggunakan digital ads juga respond dan engagement dari audiens dapat diukur, sehingga Shopee dapat melihat peningkatan jumlah pengguna Shopee setelah dibuatnya digital ads.

Keputusan Shopee menggunakan strategi cyberbranding untuk membangun awareness sebenarnya sudah sesuai dengan pengertian cyberbranding itu sendiri yang dijelaskan oleh Deirdre Breakenridge. Dalam bukunya dimana pengertian cyberbranding adalah sebuah kesempatan untuk menciptakan awareness dari suatu brand secara online, membangun pengakuan terhadap nama dan logo, mengkomunikasikan pesan dari suatu brand, mendorong traffic website, membangun identitas terhadap publik primer dan sekunder, membangun pelanggan berbasis online, meningkatkan penjualan melalui internet, dan menciptakan reputasi sehingga semakin banyak suatu brand disebut dapat memunculkan perasaan akan sebuah pengalaman yang menyenangkan.
Penyampaian informasi Shopee telah cukup baik dan sesuai dengan pengertian informasi dalam cyberbranding menurut Deindre Brekenridge. Hanya saja Shopee masih mengalami kendala terhadap para penggunanya yang sulit mengerti mengenai cara penggunaan aplikasi Shopee dan juga prosedur penggunaan fitur yang disajikan Shopee. Pengguna tersebut cenderung lebih suka bertanya kepada Customer Service Shopee dibandingkan memahami sendiri, walaupun telah dijelaskan langsung pada aplikasi Shopee tersebut.

Deindre Brekenridge menyebutkan poin ke dua setelah melakukan kegiatan memberikan informasi yakni membangun interaktivitas. Bagaimana sebuah perusahaan dapat membangun keunikan interaksi melalui online. Keunikan interaksi yang dimaksud adalah ketika komunikasi one-to-one dapat dilakukan dengan lebih mudah, informasi dapat lebih cepat menyebar, dan juga feedback yang diinginkan lebih mudah didapat. Setelah itu bagaimana Shopee membangun interaksi dengan penggunanya melalui media online, menjadi penting untuk dilakukan Shopee agar Shopee mengetahui keinginan penggunanya dan agar perkembangan yang dilakukannya dapat disesuaikan dengan kebutuhan penggunanya.

Penggunaan media sosial sebagai salah satu media untuk dapat membangun interaksi dengan penggunanya merupakan langkah yang 
sesuai dengan apa yang disampaikan oleh Lutrell. Regina Lutrell menyampaikan bahwa media sosial harus dapat dipandang sebagai bagaimana sebuah perusahaan atau sebuah brand dapat memanfaatkan secara efektif masing-masing teknologi tersebut untuk berhubungan, berinteraksi, dan membangun hubungan saling percaya dengan orang lain (Luttrell, 2015:23).

Soleh Soemirat mengatakan bahwa teknologi telah mengubah pola komunikasi PR sebelumnya yang masih konvensional seperti komunikasi dari atas kebawah, bawah keatas, horizontal, atau pola komunikasi massa. Semua itu telah mereka tinggalkan dengan pola yang lebih aktual setelah lahirnya internet. Dalam hal tersebut pula PR dan seluruh tim marketing Shopee Indonesia memanfaatkan penggunaan media sosial dengan baik terutama untuk membangun hubungan baik dengan publiknya. Shopee menyadari dengan adanya media online tentu akan mempermudah fungsi PR dalam melaksanakan tugasnya. (Soemirat \& Ardianto, 2010:191)

Penggunaan media sosial mempermudah praktisi PR untuk membangun interaksi dengan penggunanya sesuai dengan fungsi internet untuk menghilangkan batas penghalang dalam menyampaikan pesan-pesan kepada publiknya. Salah satunya pada poin komunikasi dua arah yang harus dilakukan Shopee kepada publiknya sehingga dapat membangun hubungan yang kuat dan saling bermanfaat yang tidak dapat dilakukan langsung pada media offline. (Onggo, 2004:5$6)$.

Sony Banyu Arga menjelaskan bahwa digital activity yang digunakan Shopee sudah cukup baik. Sehingga dapat membangun engagement dengan audiens, respon yang ada juga sudah sangat besar, dengan UGC (User Generated Content) yang dibuat Shopee dapat menarik perhatian audiens yang dituju. Hanya saja mengenai konten Shopee lain yang belum terlihat yakni pada penggunaan influencer. (Arga, 2017).

Arga juga menjelaskan, bahwa mengaitkan kegiatan offline dengan kegiatan online dinilai cukup efektif dalam membangun awareness. Dampak yang didapatkan akan maksimal. Pada era millennials ini informasi melalui media online akan lebih cepat tersebar sehingga untuk memaksimalkan penggunaan iklan offline ada baiknya untuk tetap dikaitkan dengan aktifitas online. Apalagi jika dilihat bahwa Shopee berbasis mobile app dimana audiensnya terdapat pada dunia digital. Pemilihan Shopee dalam membuat program kuis parody iklan Shopee tersebut dianggap cukup cerdas untuk membangun awarness Shopee Indonesia.

Poin ketiga dalam melakukan kegiatan cyberbranding menurut Deidre Brekenridge adalah insting atau membuat perbedaan. Lebih lanjut Brekenridge menjelaskan insting yang 
dimaksud adalah dimana sebuah perusahaan berusaha membuat dirinya berbeda dengan perusahaan lain dan tidak meniru upaya branding perusahaan lain baik dari isi website hingga upaya marketing yang dilakukannya. Selain itu membuat keunikan dan perberbedaan pada suatu brand merupakan salah satu karakteristik brand menurut Deidre yang juga akan menjadi salah satu kunci sukses suatu brand.

Shopee yang memposisikan diri sebagai marketplace mobile app sesuai dengan apa yang dijelaskan Rowless dalam bukunya mengenai salah satu toolkit cyberbranding. Pada poin mobile marketing yang berisi Mobile disini bukan mengenai sebuah perangkat, akan tetapi lebih ke merubah pengalaman user. Untuk menjadikan branding secara online lebih efektif diperlukan penggabungan perubahan ini dan potensi tambahan yang kompleks sebagai bagian dari masa depan. Ini berarti bahwa teknologi di belakang website perlu beradaptasi dengan cepat ke perangkat yang akan banyak digunakan user, tetapi tetap perlu memiliki hubungan langsung dengan pengalaman mereka (Rowles, 2014:114).

Shopee berusaha menggabungkan berbelanja dengan kebiasan maskasyarakat Indonesia saat ini yang gemar sekali membuka media social. Namun perbedaan yang dimiliki ini belum mampu menonjolkan perbedaan Shopee dibandingkan dengan kompetitor lain.
Seperti dikatakan Avi Tejo Bhaskoro, bahwa tokopedia yang telah memiliki mobile aplikasi sejak tahun 2014 untuk android dan meluncurkan aplikasi berbasis iOS pada tahun 2015, dan bukalapak telah meluncurkan mobile aplikasinya sejak bulan maret 2014 . (Bhaskoro, 2017).

Perbedaan ketiga yang dilakukan Shopee disampaikan melalui program yang ditawarkan oleh Shopee, Shopee berusaha membuat strategi dengan tujuan untuk dapat membangun kesadaran merek terhadap audiensnya. Melihat banyaknya kendala yang ditemui orang saat berbelanja online mengenai mahalnya biaya ongkos kirim hal itu kerap kali dialami oleh pengguna yang ingin berbelanja antar pulau. Shopee mencoba membuat sebuah program yang bertujuan untuk dapat memberikan kemudahan dalam berbelanja online dengan menghadirkan program Gratis Ongkos Kirim. Program ini ternyata cukup mampu memberikan pengaruh pada peningkatan transaksi Shopee. Sama halnya dengan yang dijelaskan oleh Icha Bella Public Relations Shopee, beberapa orang lebih mengenal Shopee karena program Gratis Ongkir yang dimilikinya. Program ini telah menjadi salah satu identitas Shopee, namun perbedaan yang dibuat Shopee ini dirasa belum cukup menjadi strategi yang kuat untuk membangun awareness melihat kompetitor Shopee yang juga memiliki program yang cukup kuat menarik untuk audiensnya. Hal 
tersebut dijelaskan oleh Vitantri Anggayasti mengatakan sejauh ini masih lebih banyak yang belum mengetahui Shopee daripada yang sudah tau, untuk itu Shopee masih terus berupaya membuat perbedaan.

\section{KESIMPULAN}

Berdasarkan uraian diatas, maka dapat disimpulan beberapa hal, sebagai berikut:

1. Shopee Indonesia dalam memberikan informasi sebagai upaya membangun brand awareness dilakukan melalui kegiatan online seperti: melalui fitur aplikasi Shopee, informasi promo, tips berjualan dan berbelanja online, dan menggunakan social media ads. Pada tahap ini dapat dikatakan Shopee telah mencapai tingkat brand recognition, mampu mempengaruhi audiens untuk memilih menggunakan Shopee.

2. Shopee Indonesia dalam membentuk interaktivitas sebagai upaya membangun brand awareness, antara lain melalui; penggunaan social media sebagai media komunikasi dengan penggunanya, interaksi melalui digital activity pada media sosial. Kegiatan yang dibuat Shopee dengan tujuan untuk membangun interaksi sudah sangat baik dilakukan, konten yang dibuat Shopee selalu berhasil dalam membangun engagement dengan pengguna. Aktivitas membangun interaksi ini juga telah dapat membawa Shopee pada tingkat brand recall dibenak penggunanya.

3. Shopee Indonesia membuat perbedaan dalam upaya membangun brand awareness, ditunjukan dengan memposisikan dirinya sebagai marketplace berbasis mobile aplikasi. Hanya saja hal tersebut belum cukup membangun awareness Shopee melihat kompetitorkompetitor Shopee juga berevolusi menghadirkan mobile aplikasi yang sekaligus juga menghadirkan fitur yang unik dan khas dari brand mereka. Perbedaan kedua yang dibuat Shopee yakni program Gratis Ongkos Kirim seIndonesia, program ini cukup berhasil meningkatkan transaksi yang terjadi di Shopee, namun program ini pun belum cukup mampu untuk menjadikan Shopee sebagai marketplace nomor satu saat ini dan menjadi top number one mobile app.

\section{DAFTAR PUSTAKA}

Anggayasti, V. (2017). Personal Interview. tim online marketing Shopee Indonesia. 27 Agustus 2017.

Arga, S. B. (2017). Personal Interview. Media analyst Media Wave Indonesia. 25 Oktober 2017.

Bella, I. (2017). Personal Interview. Public Relations Associate Shopee Indonesia. 25 Agustus 2017.

Bergstrom, A. (2000). Cyberbranding: leveraging your brand on the Internet. Strategy \& Leadership, 28(4), 10-15. https://doi.org/10.1108/108785700103 78645 
Bhaskoro, A. T. (2017). Buka Lapak Luncurkan Aplikasi Mobile dan Situs Baru. Retrieved November 15, 2017, from https://dailysocial.id/post/bukalapakluncurkan-aplikasi-mobile-dan-situsbaru

Breakenridge, D. (2001). Cyberbranding: brand building in the digital economy. London: Prentice Hall.

Fatimah, D. S. (2017). Personal Interview. Senior Public Relations Associate Shopee Indonesia. 31 Mei.

Luttrell, R. (2015). Social media: how to engage, share, and connect. Maryland: The Rowman \& Littlefield Publishing Group, Inc.

Onggo, B. J. (2004). Cyber Public Relations: Strategi Membangun dan Mempertahankan Merek Global di Era Globalisasi Lewat Media Online. Jakarta: PT. Elex Media Komputindo.

Rangkuti, F. (2009). The Power Of Brands. Jakarta: PT Gramedia Pustaka Utama.

Rowles, D. (2014). Digital branding: a complete step-by-step guide to strategy, tactics and measurement. London: Kogan Page.

Soemirat, S., \& Ardianto, E. (2010). DasarDasar Public Relations. Bandung: PT Remaja Rosdakarya.

Wulantri, P. N. (2017). Personal Interview. tim Social Media Content Shopee Indonesia. 27 Agustus 2017. 